\title{
A rare presentation of brucellosis: acute cholestatic hepatitis
}

\author{
๑Dsma Eroğlu, ๑Arzu Tarakçı \\ Konya Training and Research Hospital, Department of Infectious Diseases and Clinical Microbiology, Konya, Turkey
}

Cite this article as: Eroğlu E, Tarakçı A. A rare presentation of brucellosis: acute cholestatic hepatitis. J Health Sci Med 2021; 4(2): 243-245.

\begin{abstract}
Brucellosis can present with clinical hepatitis and rarely as acute cholestatic hepatitis. The aim of the study is to demonstrate acute cholestatic hepatitis as a rare presentation caused by Brucella melitensis. A thirty-nine-years-old male patient was admitted to our department with the complaints of fever, malaise, fatigue and sweating. At hospitalization, the temperature was $39^{\circ} \mathrm{C}$. Laboratory tests; white blood count (WBC) 4800 cells $/ \mathrm{mm}^{3}$, platelet (PLT) $173000 / \mathrm{mm}^{3}$, erythrocyte sedimentation rate (ESR) 38 $\mathrm{mm} / \mathrm{h}$, C-reactive protein (CRP) $257 \mathrm{mg} / \mathrm{L}$, alanine transferase (ALT) $284 \mathrm{U} / \mathrm{L}$, aspartate transferase (AST) 300U/L, $\gamma$-glutamyl transpeptidase (GGT) $1152 \mathrm{U} / \mathrm{L}$, alkaline phosphatase (ALP) $1762 \mathrm{U} / \mathrm{L}$, total bilirubin (T-Bil) $2.8 \mathrm{mg} / \mathrm{dL}$, direct bilirubin (D-Bil) $1.3 \mathrm{mg} / \mathrm{dL}$, lactate dehydrogenase (LDH) $705 \mathrm{U} / \mathrm{L}$. Gruber Widal test was negative. Wright serum agglutination test was found to be positive at $1 / 2560$ titer. Brucellosis should be kept in mind, especially in the differential diagnosis of the patients with acute hepatitis and cholestasis accompanied by fever.
\end{abstract}

Keywords: Acute cholestatic hepatitis, brucellosis, fever

\section{INTRODUCTION}

Brucellosis is an important zoonotic disease and a major cause of morbidity worldwide. Brucellosis may present with different clinical manifestations. The hepatic involvement in brucellosis includes a wide spectrum that ranging from mild elevation of aminotransferases to the manifestation of hepatitis. Brucellosis can present with clinical hepatitis in $3 \%$ of the cases. In addition acute cholestatic hepatitis is a very rare complication of brucella (1). Cholestatic liver disease is characterised by a typical elevation of serum alkaline phosphatase (ALP), $\gamma$-glutamyl transpeptidase (GGT) and bilirubin (2). The aim of the present study is to demonstrate acute cholestatic hepatitis as a rare presentation caused by Brucella melitensis.

\section{CASE}

A thirty-nine-years-old male patient was admitted to our department with the complaints of fever, malaise, fatigue and sweating for approximately 1 month. The patient had the history of animal husbandry, the consumption of raw milk and dairy products. Physical examination revealed yellow sclera and hepatosplenomegaly of $3 \mathrm{~cm}$ pathologically. At hospitalization, the temperature was $39^{\circ} \mathrm{C}$, the pulse was $76 / \mathrm{min}$, the respiratory rate was $18 / \mathrm{min}$ and blood pressure (BP) was $110 / 80 \mathrm{~mm} / \mathrm{Hg}$. Laboratory tests showed the following values: Hemoglobin $(\mathrm{HgB})$ $12.7 \mathrm{~g} / \mathrm{d}$, hematocrit (HCT) 34, White blood count (WBC) 4800 cells $/ \mathrm{mm}^{3}$ (neutrophils 62\%, lymphocytes $26 \%$, monocytes $10 \%$ and eosinophils $3 \%$ ), platelet (PLT) $173000 / \mathrm{mm}^{3}$, erythrocyte sedimentation rate (ESR) $38 \mathrm{~mm} / \mathrm{h}$, C-reactive protein (CRP) $257 \mathrm{mg} / \mathrm{L}$, alanine transferase (ALT) $284 \mathrm{U} / \mathrm{L}$, aspartate transferase (AST) $300 \mathrm{U} / \mathrm{L}$, GGT $1152 \mathrm{U} / \mathrm{L}$, ALP $1762 \mathrm{U} / \mathrm{L}$, total bilirubin $2.8 \mathrm{mg} / \mathrm{dL}$, direct bilirubin $1.3 \mathrm{mg} / \mathrm{dL}$, albumin $3.3 \mathrm{gr} /$ $\mathrm{dL}$ and lactate dehydrogenase (LDH) $705 \mathrm{U} / \mathrm{L}$. As the coagulation tests, the international normalized ratio (INR) and the prothrombin time (PTT) were measured as 1.1 and $16 \mathrm{~s}$, respectively. Among the viral serelogy findings, the hepatitis B surface antigen (HBs-Ag), the IgM antibody against hepatitis $B$ core antigen (anti$\mathrm{HBc} \operatorname{IgM}$ ), the anti-hepatitis A virus IgM (anti-HAV IgM), the anti-hepatitis C virus (anti-HCV), the anticytomegalovirus IgM (anti-CMV IgM), the EpsteinBarr virus anti-virus capsid antigen IgM (anti-EBV VCA IgM) and the Gruber-Widal tests were found to be negative. Autoimmune hepatitis markers (anti-smooth muscle antibody, antinuclear antibody, anti-liver/kidney microsomal antibody) were also negative. Turkey is an endemic region for brucellosis so we performed the Wright serum agglutination test, the titer was found to be positive at $1 / 2560$. Abdominal ultrasonography 
(USG) showed moderate hepatosplenomegaly, Based on these findings, acute cholestatic hepatitis due to brucella was considered. Blood cultures had been performed after the admission to hospital. Therefore, the treatment of doxycycline (100 mg every $12 \mathrm{~h}$ ) and streptomycin ( $1 \mathrm{~g}$ every $24 \mathrm{~h}$ ) was started. Brucella melitensis was isolated from blood culture on the second day of the admission to hospital. The time to defervescence was on $12^{\text {th }}$ day of the treatment. With the second week of the treatment, we observe the decrease of all elevated liver enzymes (ALT 52 U/L, AST 44 U/L, ALP 134 U/L, GGT 134 U/L) and so the patient was discharged. Then, the patient was evaluated every two weeks. During the follow-ups, the hepatic enzymes, leukocyte count, CRP and ESR were observed to return to normal limits in five weeks. The combination therapy was completed in six weeks with oral doxycycline (100 mg every $12 \mathrm{~h})+$ rifampicin (600 mg every $24 \mathrm{~h})+21$ days of streptomycin (100 mg every $12 \mathrm{~h}$ ). The laboratory features and treatment modalities are demonstrated in Table. No relapse was observed in the one-year follow-up after the treatment.

\section{DISCUSSION}

Brucella melitensis is the most pathogenic and invasive species of Brucella and more common, compared with other known species. Acute disease may include liver tenderness and mild elevation of transaminases and ALP (3).

Hepatic involvement in brucellosis includes a wide spectrum, ranging from mild elevation of aminotransferases to the manifestation of hepatitis. The hepatic involvement in brucellosis can present with clinical hepatitis in $3 \%$ of the cases. Brucella hepatitis may lead to liver decompensation and cirrhosis, if left untreated (1). Although cholestasis may occur due to the effects of proinflammatory cytokines and bacterial toxins on the bilirubin transport during bacterial infections, the exact mechanism of cholestasis in brucellosis still remains unknown (4). In a study evaluating 1028 brucellosis cases, hepatic involvement was found to be $24.8 \%$ (5). In another study involving 325 brucellosis patients with significant hepatobiliary efficacy, the clinical hepatitis was found in $284(87.3 \%)$ patients, and cholestasis was found in 215 (66.1\%) patients (1). In our report, we present an acute cholestatic hepatitis. The emergence of clinical hepatitis during the course of the disease was found to be associated with the presence of large amounts of bacteria in the liver (6). Our patient also had a significant elevation of transaminases during the hospitalization and brucella growth in blood cultures. Oztürket al reported that the greatest symptoms were; weakness in $91 \%$, fever in $86 \%$, sweating in $83 \%$ and joint pain in $79 \%$ (1). As similar with Öztürk et al. (7) the symptoms on admission were found as fever, weakness, malaise, fatigue and sweating in our case. In our study, the time to defervescence developing on $12^{\text {th }}$ day of the treatment was noteworthy. In two studies evaluating the average time to defervescence achieved by doxycycline plus rifampicin and doxycycline plus streptomycin groups was 4.2 and 3.2 days and 3.5 and 3.5 days, respectively (8).

In addition, the use of doxycycline and aminoglycoside was reported to show more rapid normalization of liver aminotransferases in clinical brucellar hepatitis cases (1). In our study, we also used the combination of doxycycline and streptomycin, and the hepatic enzymes had returned to normal limits in five weeks. No relapse was observed in the one-year follow-up after the treatment.

\section{CONCLUSION}

Brucellosis should be kept in mind, especially in the differential diagnosis of the in-patients with acute hepatitis and cholestasis accompanied by fever. An attentive anamnesis for occupational and travel history is important for early diagnosis and effective treatment resulting with lower mortality and morbidity rates.

\section{ETHICAL DECLARATIONS}

Informed Consent: Written informed consent was obtained from all participants who participated in this study.

Referee Evaluation Process: Externally peer-reviewed.

Conflict of Interest Statement: The authors have no conflicts of interest to declare.

Financial Disclosure: The authors declared that this study has received no financial support.

Author Contributions: All of the authors declare that they have all participated in the design, execution, and analysis of the paper, and that they have approved the final version.

\begin{tabular}{|c|c|c|c|c|c|c|c|c|c|}
\hline & $\begin{array}{c}\text { AST/ALT } \\
\text { U/L }\end{array}$ & $\underset{\mathrm{U} / \mathrm{L}}{\mathrm{ALP} / \mathrm{GGT}}$ & $\begin{array}{c}\mathrm{LDH} \\
\mathrm{U} / \mathrm{L}\end{array}$ & $\begin{array}{l}\text { T.Bil/D.Bil } \\
\text { mg/dL }\end{array}$ & $\begin{array}{c}\text { INR/ } \\
\text { PTT(s) }\end{array}$ & WBC/NEU & $\begin{array}{l}\text { HGB } \\
\text { g/dL }\end{array}$ & $\begin{array}{l}\text { PLT / } \\
\text { mm }^{3}\end{array}$ & CRP mg/L \\
\hline Admission & $300 / 284$ & $1762 / 1152$ & 705 & $2.8 / 1.3$ & $1.1 / 16$ & $4800 / 2640$ & 12.7 & 173000 & 257 \\
\hline Second week & $52 / 44$ & $52 / 44$ & 522 & $0.8 / 0.2$ & $0.7 / 14$ & $7200 / 4200$ & 12.2 & 230000 & 24 \\
\hline End of treatment & $18 / 32$ & $86 / 54$ & 240 & $0.6 / 0.2$ & $0.9 / 13.8$ & $6400 / 4800$ & 13.1 & 280000 & 3 \\
\hline
\end{tabular}




\section{REFERENCES}

1. Ozturk-Engin D, Erdem H, Gencer S, et al. Liver involvement in patients with brucellosis: results of the Marmara study. Eur J Clin Microbiol Infect Dis 2014; 33: 1253-62.

2. Mazokopakis EE, Papadakis, JA, Kofteridis DP. Unusual causes of intrahepatic cholestatic liver disease. World J Gastroenterol 2007; 13: $1879-82$.

3. Cervantes F, Bruguera M, Carbonell J, Force L, Webb S. Liver disease in brucellosis. A clinical and pathological study of 40 cases. Postgrad Med J 1982; 58: 346-50.

4. Fernandez-Rodriguez AM, Guindeo-Casasus MC, MoleroLabarta T, et al. Diagnosis of iron deficiency in chronic renal failure. Am J Kidney Dis 1999; 34: 508-13.

5. Buzgan T, Karahocagil MK, Irmak H, et al. Clinical manifestations and complications in 1028 cases of brucellosis: a retrospective evaluation and review of the literature. Int J Infect Dis 2010; 14: 469-78.

6. Uluğ $M$, Celen MK, Ayaz C. An unusual presentation of brucellosis: acute hepatitis. Braz J Infect Dis 2010; 14: 641-2.

7. Ariza J, Gudiol F, Pallares R, et al. Treatment of human brucellosis with doxycycline plus rifampin or doxycycline plus streptomycin. A randomized, double-blind study. Ann Intern Med 1992; 117 25-30.

8. Colmenero Castillo JD, Hernandez Marquez S, Reguera Iglesias JM, Cabrera Franquelo F, Rius Diaz F, Alonso A. Comparative trial of doxycycline plus streptomycin versus doxycycline plus rifampin for the therapy of human brucellosis. Chemotherapy 1989; 35: 146-52. 